\title{
Empirical Exploration of a Unified Model of Task-Specific Motivation
}

\author{
Cornelis J. de Brabander ${ }^{1,2}$, Rob L. Martens ${ }^{2}$ \\ ${ }^{1}$ Educational Studies, Leiden University, Leiden, The Netherlands \\ ${ }^{2}$ Welten Institute, The Open University of the Netherlands, Heerlen, The Netherlands \\ Email: Brabander@fsw.leidenuniv.nl
}

How to cite this paper: de Brabander, C. J., \& Martens, R. L. (2018). Empirical Exploration of a Unified Model of Task-Specific Motivation. Psychology, 9, 540-560.

https://doi.org/10.4236/psych.2018.94033

Received: February 13, 2018

Accepted: April 6, 2018

Published: April 9, 2018

Copyright $\odot 2018$ by authors and Scientific Research Publishing Inc. This work is licensed under the Creative Commons Attribution International License (CC BY 4.0).

http://creativecommons.org/licenses/by/4.0/

\begin{abstract}
The aim of this investigation was to explore the merits of the Unified Model of Task-specific Motivation (UMTM). As in this model task-specific components from several partly conflicting theories were integrated, this study constitutes an important contribution to the further development of consensus about motivation theory. Four relatively independent types of valences are the core of the UMTM. Affective and cognitive valences represent feelings while doing an activity and thoughts about the value of its consequences respectively; both types of valences can be positive and negative, hence calling for approach and avoidance motivation respectively. The interaction between these four categories of valences results in a valence expectation, which influences readiness for action. Valences in turn are influenced by four categories of task-specific antecedents, namely appraisals of autonomy, feasibility, and social relatedness, and subjective norm. The global question we tried to answer was to what extent motivational data on specific activities could be modeled in accordance with the UMTM and how different, specific activities affect the influence that the components of the model exert. Structural equation modeling of questionnaire responses of 335 teachers on all components of the model except negative valences with respect to three imaginary types of professional learning activities (formal training, personal study, and reflection on practice) revealed that characteristics of the task determine to what extent components of the model come into play. It is concluded that the model represents a first promising step towards reuniting conflicting theories of motivation.
\end{abstract}

\section{Keywords}

Motivation, Autonomy, Self-Efficacy, Professional Development, Teachers

\section{Introduction}

In the field of educational psychology, and not only there, we notice a vast proli- 
feration of theories of motivation (Boekaerts, van Nuland, \& Martens, 2010; Schunk, Pintrich, \& Meece, 2008). On first sight, these theories appear to conflict in different ways. De Brabander and Martens (2014) proposed a reconciliation of apparent controversies and developed a Unified Model of Task-specific Motivation (UMTM). The aim of this article was to explore the merits of this model using the area of professional development of teachers as an exemplary instance. As in the UMTM different, partly conflicting theories of motivation were integrated, this study constitutes an important and much needed contribution to the further development of consensus about motivation theory. The development of the model is extensively expounded by De Brabander and Martens (2014). Here we present a concise summary.

Obviously, the UMTM does not cover all aspects of motivation. The aim of the UMTM was to identify the constructs that are essential for the description of a person's task-specific motivation at a given moment in time. Such a description would provide a cross section of the structure of a person's motivation for a rather specific activity at a given point in time. The model does not refer to motivation for broad fields of action like sports or mathematics, but is applicable to more specific acts like reading job relevant books or papers. The focus on specific tasks implies also that the model does not cover relatively stable dispositions or traits that influence task-specific motivation. Furthermore, as an aid to its development, the model concentrates on motivation for action options that are open to the actor in the near future. Left out are motivational aspects that enter the game once the actor has decided to start an activity. And it does not pay attention to feedback loops from past activities, which of course play an important role in the build-up of task-specific motivation on future occasions.

The constituent parts of the UMTM stem from or are suggested by several motivation theories, like the self-determination theory (Deci \& Ryan, 2000; Ryan \& Deci, 2000a, 2000b), the flow theory of Csikszentmihalyi (1990), the person-object theory of interest proposed by Krapp (2002; 2005), and several expectancy-value theories, namely the social-cognitive theory of Bandura (1977; 1986; 1992; 1997), the expectancy-value theory of achievement motivation (Wigfield \& Eccles, 2000), and the theory of planned behavior of Ajzen and Fishbein (Ajzen, 1991; Ajzen \& Fishbein, 2008). The reasons for the selection of these theories and the exclusion of others are clarified by De Brabander and Martens (2014).

\subsection{A Unified Model of Task-Specific Motivation (UMTM)}

The model is depicted in Figure 1. De Brabander and Martens (2014) define motivation as readiness for action. It is a certain level of willingness to enter the execution of an activity. Actual performance of the action is included in the model as to remind us of its existence, but the model does not engage in it, or in any of its determinants other than readiness for action. The most important determinant of readiness for action is a valence expectation, the estimated value a 


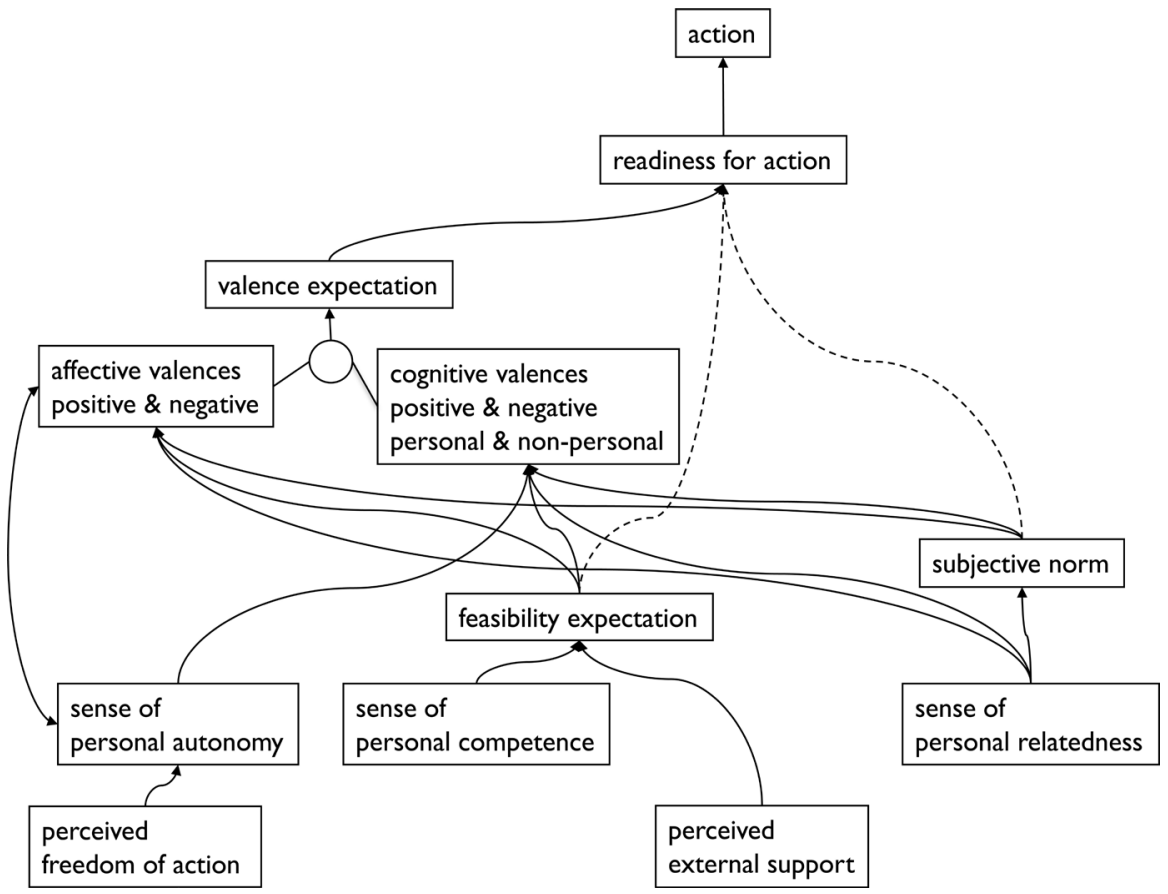

Figure 1. Outline of the Unified Model of Task-specific Motivation (de Brabander \& Martens, 2014).

person attributes to an activity. Valence expectation is the result of four interacting but separate and therefore relatively independent mental processes. These four processes are defined by a classification of valences along two dimensions, affective versus cognitive, and positive versus negative.

Affective valences are produced by an affective regulation system of behavior. Cognitive valences are produced by a cognitive behavioral regulation system (Epstein, 1994; Krapp, 2002; 2005). Affective valences are defined as the affective experiences that the actor anticipates when undertaking an activity (cf. intrinsic motivation in self-determination theory, flow in flow theory, and intrinsic value in the expectancy-value theory of achievement motivation). In the UMTM affective valences are the level of pleasure one expects to experience when doing an activity. Affective valences surface as a certain level of liking to do an activity. They are automatic (unavoidable) and mechanical, that is unintentional, responses to an action "object" the person apperceives (in the near future). Any action that comes to mind immediately brings about feelings about that action. The important characteristic of affective valences is not that they have no reason or function, but that their reason or function is not necessarily known and often is not known. Cognitive valences are defined in the UMTM as the articulation and valuation of expected consequences of an activity after performance (cf. attainment value and utility value in the expectancy-value theory of achievement motivation, attitude toward behavior in the theory of planned behavior, outcome expectancies in the social cognitive theory). Cognitive valences are explicit and brought about by active reflection of the prospective actor. Every activity has multiple consequences, each of which will have its own cognitive valence(s). The 
quality of cognitive valences, of course, depends on the actor's anticipatory competence. In the UMTM cognitive valences are broken up in different categories depending on who will acquire the expected outcome value. The first one that profits from an activity, obviously, is almost always the acting person himself or herself. What other categories of cognitive valences need to be distinguished depends on the specific context. In the context of education with teachers as acting persons, the student and the school as an organization are natural candidates. In other contexts non-personal parts of cognitive valences will have different labels. Affective valences may also have different parts, because some parts of an activity may be pleasurable, while others may be less pleasurable, but affective valences have no non-personal component. Only the extent to which a person self feels attracted to an activity is relevant for his or her readiness for action.

An important field of conflict between different motivation theories is the relation between affective and cognitive valences. In self-determination theory affective and cognitive valences are oppositional endpoints on a single dimension: completely intrinsic to completely extrinsic. Expectancy ${ }^{\star}$ value theories blur the distinction: intrinsic value is just another type of subjective value. The UMTM follows the solution that Krapp $(2002 ; 2005)$ proposed by defining affective valences and cognitive valences as two theoretically independent categories of motives that emanate from two interacting, but distinct systems of behavior regulation. What is pleasurable to do, is in general also recognized as profitable and vice versa, but discrepancies between the two are possible ("I know it is good for me, but I absolutely don't feel like it") and it is de merit of self-determination theory to have demonstrated the adverse effects of these discrepancies on performance quality, self-esteem, and general well-being (Ryan \& Deci, 2000a). Viewing affective and cognitive valences as discrete but related implies that sometimes they reinforce each other and sometimes they counteract each other, and that readiness for action consequentially depends on the specific configuration of the two types of valences.

A non-controversial, or at least less controversial distinction in motivation theories is that between approach and avoidance motivation (Elliot, 2006; Elliot \& Church, 1997). This contrast generally refers to the possibility of valences to be positive or negative. Negative valences call for refraining from an action (or for initializing counteractions) in order to prevent their realization. In contrast, positive valences call for activities that promise to realize them. Approach and avoidance motivation are also believed to be managed by "two partially distinct self-regulatory systems" (Carver, 2006: p. 105; cf. also Lang, Bradly, \& Cuthbert, 1998). Carver also refers to the presumption, which first emerged in the 1940's and 1950's, that these systems are based on different structures in the nervous system. This is as yet the most popular hypothesis, even though it is still only partially supported by the literature (Elliot \& Covington, 2001). Moreover, the effects of the two types of motivation are very different. Avoidance motivated 
action can maximally result in maintenance of the status quo and is generally stressful, whereas approach motivated action leads to enrichment and is generally pleasant (Carver, 2006).

Combining the distinction between approach and avoidance motivation with the distinction between affective and cognitive valences thus allows for four relatively independent sources of behavior regulation. Affective and cognitive valences are not one-dimensional running from negative through neutral to positive, but are composed of two dimensions: level of positive valences and level of negative valences. Affective and cognitive valences, both consisting of positive and negative valences combine in a resultant value, labeled valence expectation, which in turn determines readiness for action. Such a conceptualization is very much compatible with the notion of multiple consequences (including costs!) combining into an overall level of cognitive valence of an act or a course of action. And the overall level of affective valence presumably also has multiple aspects. Some aspects of an act may be pleasurable, while other aspects may be less pleasurable and even unpleasant (in varying degrees). This fourfold conceptualization thus promises to provide more and better possibilities for the explanation of complex motivational phenomena.

All selected theories of motivation include one or more immediate antecedents of valences. It is important to note that the treatise of these antecedents in the UMTM is limited to their task-specific aspects, which is not necessarily the case in contributing theories. According to self-determination theory, intrinsic motivation depends on three conditions that are related to important psychological needs: autonomy, competence and relatedness. Autonomy refers to the origin of the action: the person or a foreign force. Feasibility-that in the UMTM replaces the concept of competence for reasons that will become clear below-concerns the question whether it is possible to complete an activity successfully. Relatedness refers to the level of belongingness between the people that participate in the activity context. Translated to task-specific motivation, there are a lot of possible relations between these need-related conditions with action valences, but for the moment and in the context of professional development, the UMTM assumes that they all contribute to all kinds of valences. That is to say, that a higher level of situation-specific autonomy, feasibility and relatedness lead to increased task-specific motivation, because they affect affective and cognitive valences.

Of the three conditional factors identified, only feasibility stages in expectancy-value theories. And, in different theories, its role is differently conceived. In social cognitive theory feasibility has a mediating role: higher feasibility results in better performance expectations and therefore higher valence expectations. In the expectancy-value theory of achievement motivation and in the theory of planned behavior feasibility directly influences the level of task-specific motivation. The UMTM leaves both options open, though the mediated effect is attributed more explanatory power: it is not clear how the sheer opportunity to per- 
form successfully as such would increase readiness for action.

From the theory of planned behavior the UMTM borrows yet another component that is assumed to influence readiness for action, namely subjective norm, which entails the inclination to abide by the task-related norms of important others. To the extent that important others think that a specific activity ought to be performed, readiness for action will be higher. An open question is again, whether this is a direct effect or an effect that is mediated through valences. Activities that are strongly supported by the reference group may have more positive and less negative affective and cognitive valences. However, it is also possible that people participate in an activity, just because significant others would approve of their performance, which is the position of the theory of planned behavior. Evidently, subjective norm will be influenced by relatedness.

A particular feature of the UMTM is the distinction between the person and his or her context, which leads to a partition of some components in the model. The distinction between personal and non-personal cognitive valences was introduced above already. In addition also autonomy and feasibility have a personal and a situational facet. The personal facet of autonomy is labeled sense of personal autonomy and is defined as the extent to which the person experiences him or herself as the originating force that drives performance of an activity. The distinction here is whether the self feels driving of driven. The situational part of autonomy is labeled perceived freedom of action and entails the liberty a person perceives in the action context to decide independently about choice and execution of action alternatives (cf. Reeve, Nix, \& Hamm, 2003). The two aspects are obviously related. Their fundamental distinctiveness, however, is disclosed by the possibility that one can still experience the self as the driving force in a situation where one has no freedom of action. That possibility is also the reason why it is assumed that sense of personal autonomy is the determining factor and that in a specific situation perceived freedom of action is important to the extent it contributes to sense of personal autonomy. Notice again that at issue here are only situation-specific factors. The role of a more general freedom of action (for instance at the level of the school in general) might very well be different. Furthermore, it is speculated that sense of personal autonomy is differently related to different types of valences. Sense of personal autonomy affects cognitive valences, but sense of personal autonomy and affective valences are seen as reciprocally related. If I experience myself as origin of my actions, it is very likely that I also experience pleasure during performance, and the other way around: if I experience pleasure performing an activity, it is very likely that I experience a sense of agency. In concrete situations, sense of personal autonomy and affective valences act to some extent like communicating vessels.

Feasibility has also two sides. The personal side of feasibility is sense of personal competence and refers to the estimate of personal capacities, knowledge and skills that are available to complete an activity at a specific level of performance. The situational part, an estimate of circumstances that hinder or support 
performance of a specific activity, is called perceived external support (de Brabander, Rozendaal, \& Martens, 2009; Imants \& de Brabander, 1996; Smit, de Brabander, \& Martens, 2014). Both are needed for successful performance, which is why expected feasibility is conceived as the result of both components. It is expected, however, that sense of personal competence in general will supply the higher contribution of the two, because, for instance, people can overcome hindrances and obstacles by stepping up their effort.

In the UMTM the distinction between person and context is not applied to relatedness, though theoretically, that would be possible. However, the contextual part (the level of relatedness one perceives between the participants of an activity) is not attributed a distinctive role. Therefore, the model is restricted to the personal part: sense of personal relatedness (the level of relatedness one personally feels with other participants in an activity).

Relatedness is different from the other conditional factors, not theoretically, but practically. Certainly in educational settings, the group of people that constitute the action context is relatively stable across tasks. Only when the people that participate in a specific activity are different from the people in the wider job context, it would be possible to distinguish between task-specific relatedness and team level relatedness. In practice then, sense of personal relatedness is often less task-specific than autonomy and feasibility.

\subsection{An Exploratory Application to Professional Learning Activities}

We applied the model described above to motivation for three exemplary professional learning activities. We did not have in this paper any interest in professional development per se. We had an opportunity to use motivational data on professional learning activities from an evaluation study of a web site designed to promote professional development of teachers (de Brabander, Vinken, \& van Wolput, 2011).

According to Kwakman (2003), there is much agreement in the literature on activities that contribute to professional development. From the literature she derived four categories of learning at the workplace: reading, experimenting, reflecting, and collaborating. Based on this classification we defined two exemplary groups of activities that we expected to be familiar to teachers at different educational levels:

- Personal Study (PS)-Searching and acquiring knowledge from diverse information sources, like literature, research, and internet;

- Reflection on Practice (RP)-Reflecting with colleagues on current educational and instructional practices.

In the area of professional learning we may witness a development where traditional types of learning in formal courses are being replaced by workplace learning (Kwakman, 2003). However, a large part of learning by professionals still takes the form of formal training. Therefore, we added a third category of professional learning activities: 
- Formal Training (FT)-Participation in formal courses, in-service training, and internships.

In this empirical exploration of the UMTM no data were collected on negative valences. Furthermore, in this study the respondents were questioned about professional learning activities they had engaged in the past. Thus, the data described the motivation for a specific type of professional learning activities at a specific moment in the past. Also, having no data on readiness for action, we used data on actual participation in different types of activities as a replacement. And finally, in the evaluation study the relatedness component was questioned not as sense of personal relatedness, but as perceived relatedness. As these constructs are not very distinctive (see also the description of relatedness in the UMTM above, we used perceived relatedness in our analysis as a substitute for sense of personal relatedness.

Our global question to be answered in this exploratory application of the model was to what extent motivational data on specific activities could be modeled in accordance with the UMTM and how different, specific activities affect the influence that the components of the model exert. From this overall question we developed a couple of heuristic questions. In the first place we wanted to examine to what extent all the task-specific immediate antecedents influence both affective and cognitive valences. Secondly, we wondered whether the personal and contextual facets of autonomy and feasibility could be modeled as theoretically conceived: feasibility expectation as a combination of sense of personal competence and perceived external support, perceived freedom of action as mediated by sense of personal autonomy, and sense of personal autonomy as mutually related to affective valence. An important question was also whether immediate antecedents influence actual participation mediated through valences or also directly.

\section{Method}

\subsection{Sample}

The sample consisted of 335 teachers from primary (38\%), secondary general (44\%) and secondary vocational (18\%) education who accepted a general invitation to respond to an internet questionnaire. The sample was divided in $61 \%$ women and 39\% man. The average age of the respondents was 47.79 (SD = 9.707). Their average years of experience was $18.3(\mathrm{SD}=11.375)$.

\subsection{Variables}

The selected components of the theoretical model except perceived relatedness were translated into a single question using a bipolar seven-point scale (Table 1). This set of questions was administered three times, once for each of the three types of professional learning activities, formal training (FT), personal study (PS), and reflection on practice (RP). Each part of the questionnaire was preceded by a description of the category of activities as given above. 
Table 1. Item formulations for task-specific components.

\begin{tabular}{|c|c|c|}
\hline Task-specific component & & tem \\
\hline \multirow{2}{*}{$\begin{array}{l}\text { sense of personal autonomy } \\
\text { (spa) }\end{array}$} & I would participate in these activities, because... & \\
\hline & I myself want to do so & - other people expect me to. \\
\hline \multirow{2}{*}{$\begin{array}{l}\text { perceived freedom of action } \\
\text { (pfa) }\end{array}$} & The decision to participate in these activities... & \\
\hline & is to me & - is taken by others. \\
\hline \multirow{2}{*}{$\begin{array}{l}\text { sense of personal competence } \\
\qquad(\mathrm{spc})\end{array}$} & I feel... & \\
\hline & perfectly capable to perform this activity successfully & - hardly capable to perform these activities successfully. \\
\hline \multirow{2}{*}{$\begin{array}{l}\text { perceived external support } \\
\text { (pes) }\end{array}$} & The conditions in our school... & \\
\hline & hamper a fruitful participation in these activities & - promote a fruitful participation in these activities. \\
\hline \multirow{2}{*}{ subjective norm $(\mathrm{sn}) \mathrm{d}$} & Colleagues of my school, whom I feel connected to... & \\
\hline & would applaud my participation in this activity & - would be indifferent to my participation in this activity. \\
\hline \multirow{2}{*}{ affective valence (av) } & From these activities I would derive... & \\
\hline & much pleasure & - little pleasure. \\
\hline \multirow{2}{*}{ personal profit (pp) } & What I learn from these activities, seems me to be... & \\
\hline & worthwhile for myself & - worthless for myself. \\
\hline \multirow{2}{*}{ student profit (sp) } & What I learn from these activities, seems me to be... & \\
\hline & worthwhile for the students & - worthless for the students. \\
\hline \multirow{2}{*}{ institutional profit (ip) } & What I learn from these activities, seems me to be... & \\
\hline & worthwhile for the school & - worthless for the school. \\
\hline
\end{tabular}

Table 2. Fit measures of confirmatory factor analyses of task-specific components.

\begin{tabular}{cccccc}
\hline model & $\chi^{2}$ & $d f$ & NNFI & CFI & RMSEA \\
\hline 1) 9 factors & 1485.52 & 288 & .427 & .530 & .124 \\
2) $9+3$ factors & $354.25 \mathrm{~d}$ & 258 & .949 & .962 & .037 \\
\hline
\end{tabular}

We applied confirmatory factor analysis using EQS (Bentler, 2008) to determine the final variables. We compared two models. In the first model the categories of professional learning activities were conceived as representative instances of one underlying construct, professional learning activities. This model consisted of nine factors, one for each task-specific component of the theoretical model. The second model was in fact a multitrait-multimethod model, because in addition to a weight for the task-specific components also a weight for the specific activity category was estimated. This model thus contained 12 factors ( 9 task-specific components and 3 types of professional learning activities). In both models the correlations between factors were left free. We used robust maximum likelihood estimation. The fit measures of the two models showed that only the second model was acceptable (Table 2). The correlations between the three factors for the categories of professional learning activities in that model indicated that the types of activities were not homogeneous: between the FT and 
PS factors $r=.193$, between the FT and RP factors $r=.368$, and between the PS and RP factors $r=.142$. Consequently, as one overall analysis to test our theoretical model was impossible we analyzed each type of professional learning activity separately.

We asked the respondent, furthermore, to what extent he or she typically participated in the three types of professional learning activities, offering a choice from four alternatives: never, sometimes, regularly, and often. The correlations between participation measures confirmed the limited association between types of learning activities. Between FT and PS $r=.267$, between FT and RP $r=.172$, and between PS and RP $r=.236$.

As explained earlier, perceived relatedness with colleagues (pr) stages not at the task level, but at the school level, and was measured as the level of social cohesion among colleagues. Three questions measured perceived relatedness, an example being: "In general our team is highly cooperative". Respondents could choose on a five-point scale between "Not at all" to "Very much so". The reliability of this scale according to Cronbach's alpha was $\alpha=.855$.

\subsection{Analysis}

The relations between the components of our theoretical model were analyzed with structural equation models using EQS (Bentler, 2008). For each category of professional learning activities we built a separate model. In each case the first model was based on the theoretical model in Figure 1. Feasibility expectation (fe) was modeled as a latent factor based on sense of personal competence (spc) and perceived external support (pes). Cognitive valence was also modeled as a latent factor based on personal (pp), student (sp) and institutional (ip) profit. A third latent factor, valence expectation (ve) was modeled based on affective valence (av) and cognitive valence (cv). The hypothesized reciprocal relation between sense of personal autonomy (spa) and affective valence was modeled as a correlation between the error terms of the two variables.

Based on Wald and Lagrange Multiplier tests and on standardized residuals parameters were dropped and added as long as the model could be improved. In all models we used robust maximum likelihood estimates because much of our variables did not satisfy all normality assumptions (Table 3 and Table 4).

Table 3. Distribution characteristics of professional learning activities and perceived relatedness.

\begin{tabular}{|c|c|c|c|c|c|c|c|}
\hline & \multirow{2}{*}{$\mathbf{N}$} & \multirow{2}{*}{ Mean } & \multirow{2}{*}{ SD } & \multicolumn{2}{|c|}{ Skewness } & \multicolumn{2}{|c|}{ Kurtosis } \\
\hline & & & & Value & $S E$ & Value & $S E$ \\
\hline FT & 334 & 2.97 & .780 & -.067 & .133 & -1.073 & .266 \\
\hline PS & 333 & 3.26 & .777 & -.646 & .134 & -.568 & .266 \\
\hline $\mathrm{RP}$ & 333 & 3.08 & .760 & -.463 & .134 & -.239 & .266 \\
\hline $\mathrm{pr}$ & 334 & 3.39 & .836 & -.546 & .133 & -.151 & .266 \\
\hline
\end{tabular}


Table 4. Distribution characteristics of task-specific components.

\begin{tabular}{|c|c|c|c|c|c|c|c|}
\hline & \multirow{2}{*}{$\mathbf{N}$} & \multirow{2}{*}{ Mean } & \multirow{2}{*}{$\mathrm{SD}$} & \multicolumn{2}{|c|}{ Skewness } & \multicolumn{2}{|c|}{ Kurtosis } \\
\hline & & & & Value & $S E$ & Value & $S E$ \\
\hline \multicolumn{8}{|c|}{ Formal Training } \\
\hline spa & 331 & 2.12 & 1.438 & 1.459 & .134 & 1.559 & .267 \\
\hline $\mathrm{pfa}$ & 334 & 2.59 & 1.663 & .890 & .133 & -.155 & .266 \\
\hline $\mathrm{spc}$ & 333 & 1.85 & 1.046 & 1.804 & .134 & 4.090 & .266 \\
\hline pes & 332 & 4.48 & 1.741 & -.345 & .134 & -.774 & .267 \\
\hline sn & 334 & 2.90 & 1.514 & .659 & .133 & -.051 & .266 \\
\hline av & 333 & 2.10 & 1.101 & 1.199 & .134 & 2.049 & .266 \\
\hline $\mathrm{pp}$ & 327 & 1.80 & .984 & 1.568 & .135 & 3.330 & .269 \\
\hline $\mathrm{sp}$ & 330 & 1.89 & .982 & 1.415 & .134 & 3.141 & .268 \\
\hline ip & 332 & 1.95 & 1.018 & 1.219 & .134 & 1.988 & .267 \\
\hline \multicolumn{8}{|c|}{ Personal Study } \\
\hline spa & 331 & 1.65 & 1.035 & 2.046 & .134 & 4.873 & .267 \\
\hline $\mathrm{pfa}$ & 334 & 1.57 & .974 & 2.332 & .133 & 6.931 & .266 \\
\hline $\mathrm{spc}$ & 333 & 1.65 & .934 & 1.980 & .134 & 5.695 & .266 \\
\hline pes & 332 & 4.38 & 1.820 & -.104 & .134 & -1.085 & .267 \\
\hline sn & 333 & 2.94 & 1.589 & .665 & .134 & -.189 & .266 \\
\hline av & 329 & 2.07 & 1.075 & .970 & .134 & .723 & .268 \\
\hline $\mathrm{pp}$ & 332 & 1.67 & .830 & 1.266 & .134 & 1.453 & .267 \\
\hline $\mathrm{sp}$ & 328 & 1.72 & .864 & 1.405 & .135 & 2.554 & .268 \\
\hline ip & 329 & 1.89 & .927 & .958 & .134 & .763 & .268 \\
\hline \multicolumn{8}{|c|}{ Reflection on practice } \\
\hline spa & 332 & 2.10 & 1.345 & 1.427 & .134 & 1.784 & .267 \\
\hline $\mathrm{pfa}$ & 334 & 2.42 & 1.510 & 1.049 & .133 & .529 & .266 \\
\hline $\mathrm{spc}$ & 334 & 1.94 & 1.173 & 1.640 & .133 & 3.339 & .266 \\
\hline pes & 330 & 4.18 & 1.790 & -.058 & .134 & -1.044 & .268 \\
\hline sn & 334 & 2.62 & 1.400 & .766 & .133 & .171 & .266 \\
\hline av & 331 & 2.26 & 1.221 & .973 & .134 & .884 & .267 \\
\hline $\mathrm{pp}$ & 331 & 1.84 & 1.071 & 1.544 & .134 & 3.069 & .267 \\
\hline $\mathrm{sp}$ & 330 & 2.05 & 1.138 & 1.218 & .134 & 1.776 & .268 \\
\hline ip & 332 & 1.99 & 1.145 & 1.360 & .134 & 2.395 & .267 \\
\hline
\end{tabular}

\section{Results}

\subsection{Descriptive Statistics}

Table 3 reports the characteristics of the distribution of participation in three types of professional learning activities and of perceived relatedness.

In Table 4 the distribution characteristics of the task-specific components 
were collected using the original scoring with a score of 1 through 7 from the leftmost to the rightmost answer option (cf. Table 1). Table 1 and Table 2 show that scores of sense of external support are reversed in comparison to all other items. To ease interpretation in subsequent analyses all scores were adapted such that a high score represents a high level of the variable involved.

\subsection{Relations between Variables}

For each category of professional learning activities we developed a model of the relations between the variables. Table 5 presents the fit measures of the three final models. The three models are depicted in Figures 2-4.

First we present the results that the three models have in common. In all models we found that spa and fe were related to the two types of valences, but

Table 5. Fit measures of final models for each of three categories of professional learning activities.

\begin{tabular}{cccccc}
\hline model & $\chi^{2}$ & df & NNFI & CFI & RMSEA \\
\hline Formal Training (FT) & 50.84 & 35 & .967 & .979 & .043 \\
Personal Study (PS) & 50.00 & 34 & .971 & .982 & .039 \\
Reflection on Practice (RP) & 41.27 & 29 & .972 & .985 & .037 \\
\hline
\end{tabular}

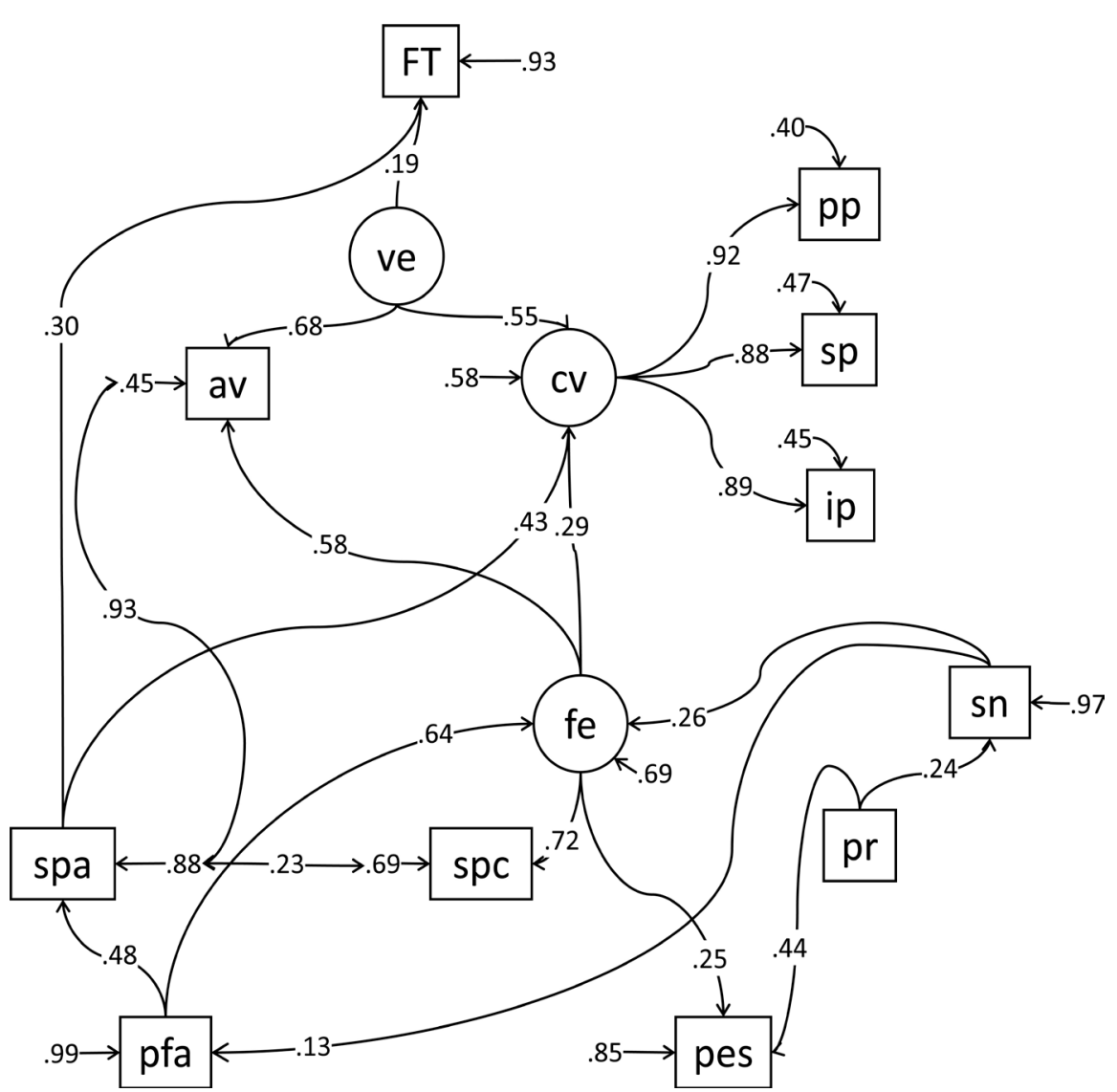

Figure 2. Final structural model of motivational variables bearing on Formal Training activities. 


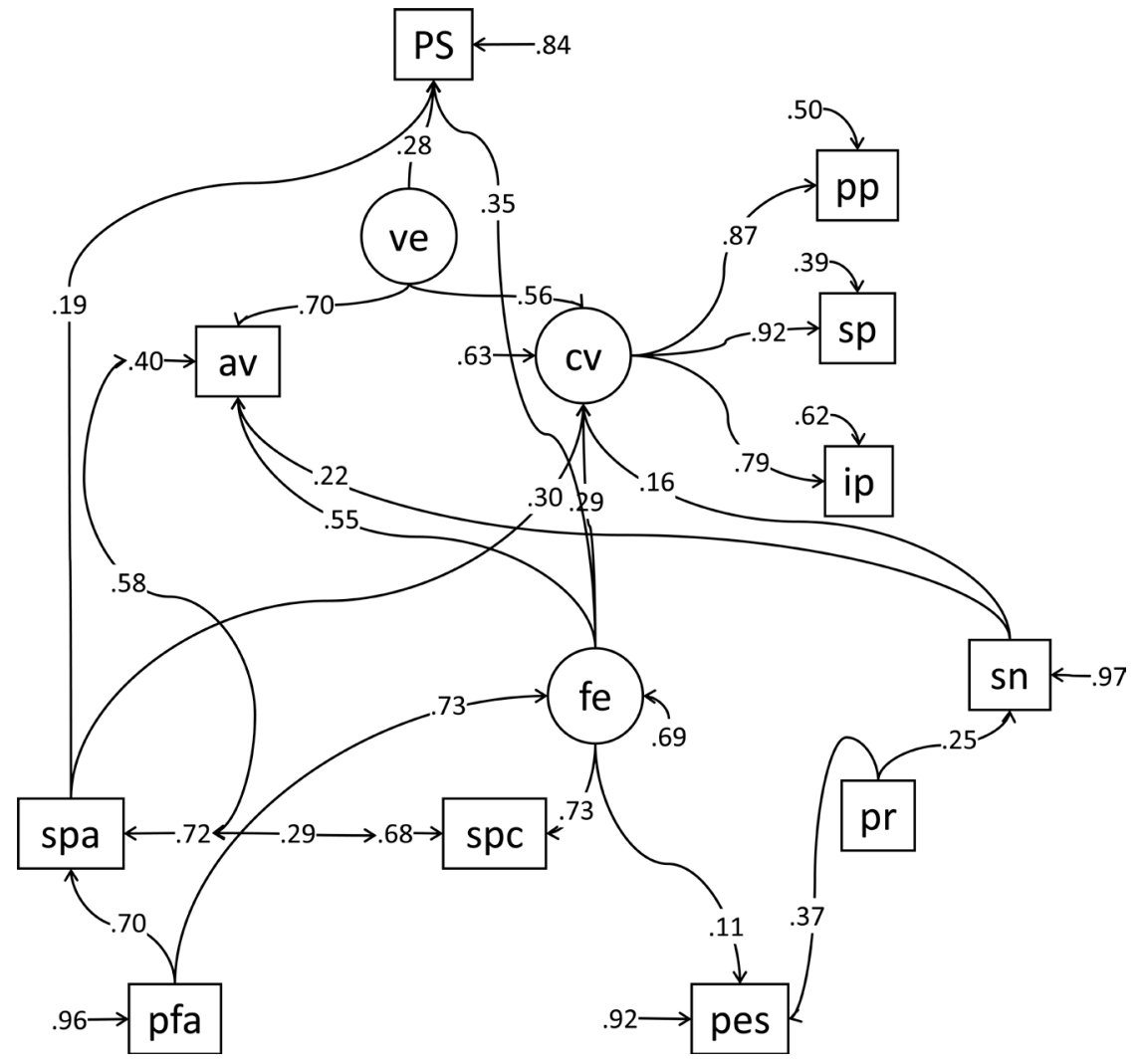

Figure 3. Final structural model of motivational variables bearing on Personal Study activities.

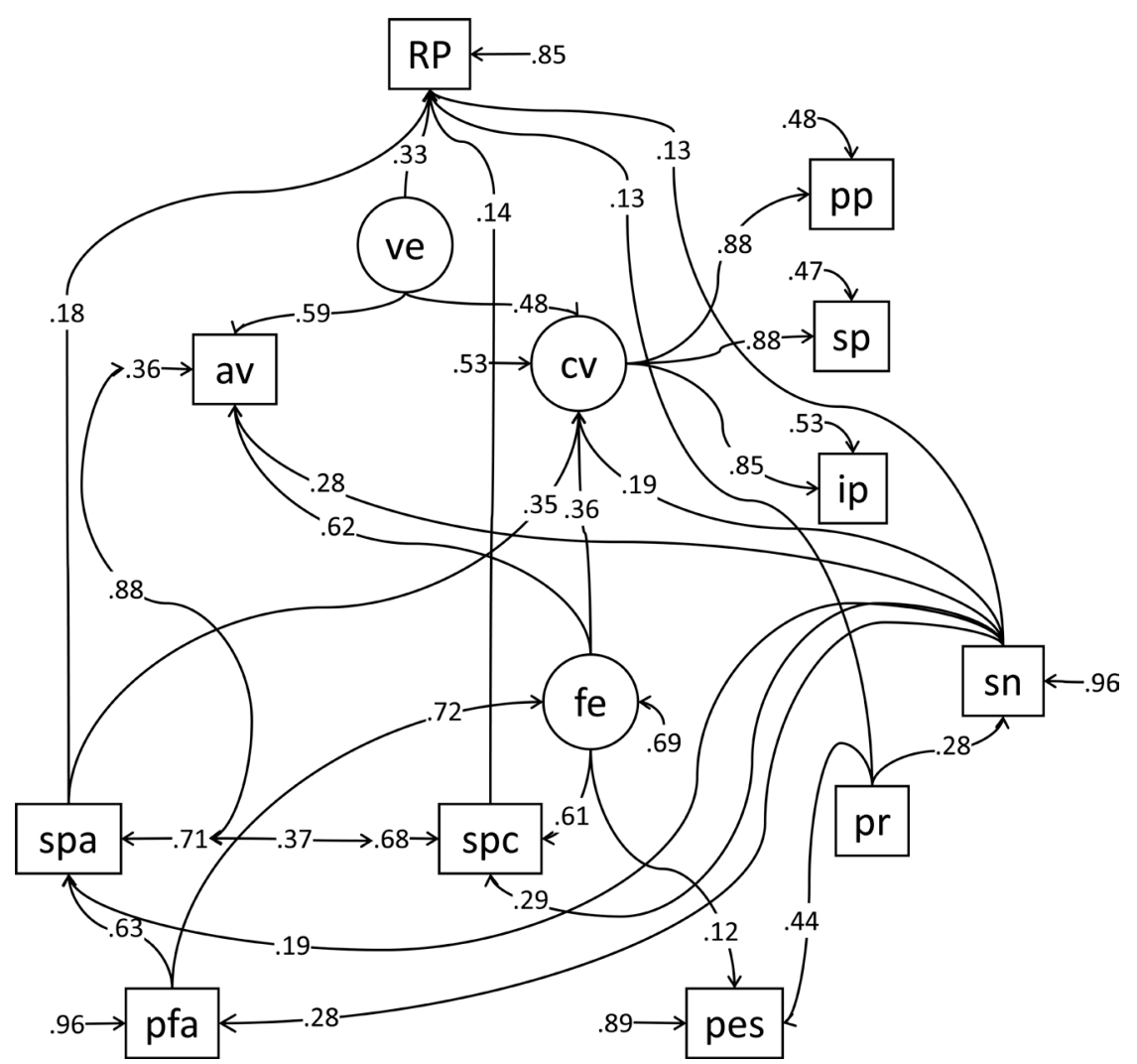

Figure 4. Final structural model of motivational variables bearing on Reflection on Practice activities. 
both had a higher path coefficient to av than to cv. However, pr had no direct path to valences. Instead its modest influence was mediated by sn and contributed to pes. The correlation between error terms of spa and av were high to very high. The effect of pfa was mediated by spa, but also and sometimes even more pronounced by fe. In turn, fe as latent factor was based on spc and pes, in which combination spc clearly carried more weight. The latent factor $\mathrm{cv}$ was a combination of pp, sp, and ip, in which all manifest variables had a very high coefficient. The two valences, av and cv combined into ve with a slightly higher coefficient for av. In the three models, ve had a small to moderate contribution to make to participation in professional learning activities. A direct path connected spa to participation in professional learning activities. Finally, error terms of spa and spc were correlated.

There were also notable differences between the three models. The majority of these differences were bound to the role of sn. In the FT model there was no path of sn to valences directly, but only through fe and pfa. These paths of influence were absent in the PS model, where sn instead modestly influenced av and cv. In the RP model sn revealed its broadest impact with influence paths to av and cv, to pfa, spa, and spc, and also directly to RP. The PS model revealed a direct contribution of fe to PS that had a counterpart in the RP model in the form of a direct influence of spc on RP. Finally, the RP model contained a small direct path of pr to RP.

\section{Discussion}

From the resemblances between the three models, we may conclude that our empirical data by and large supported the Unified Model of Task-specific Motivation. Sense of personal autonomy and feasibility expectation were related to affective valences and to cognitive valences as expected. The high correlation between the error terms of affective valences and sense of personal autonomy fitted the reciprocal relation between them as conceptualized in the theoretical model. Feasibility contributed also to affective valences, and, at a slightly lower level compared to their relation with affective valences, both components contributed to cognitive valences. Contrary to expectation, however, we did not find a constant contribution of the social components in the model to the two types of valences. Perceived relatedness was in none of the three models connected to valences. Subjective norm contributed in two models, the Personal Study model and the Reflection on Practice model, to affective and cognitive valences. Although the differences were small, here too the pattern corresponded to all other contributions to valences, as the path coefficients of subjective norm for affective valences in both models were slightly higher than for cognitive valences.

It was hypothesized in the model that the influence of perceived freedom of action was mediated by sense of personal autonomy. This mediation was corroborated by the data, though to a substantial extent also through an unexpected path. Perceived freedom of action influenced sense of personal autonomy mod- 
erately to strongly in the three models, however, it revealed in all models also an influence on feasibility expectation at least as strong or stronger.

It proved also possible to model feasibility expectation as a combination of sense of personal competence and perceived external support. As hypothesized, sense of personal competence was the more important of the two, but the contribution of perceived external support appeared to be smaller than expected.

We had not expressed the reciprocal relation between sense of personal autonomy and sense of personal competence explicitly in advance, but it was a natural addition: feeling competent and feeling autonomous mutually enhance each other.

Cognitive valences could be modeled as a combination of personal, student, and institutional profit. The very high path coefficients we obtained indicated, however, that there was hardly any differentiation between the three types of profit.

Furthermore, valence expectation could be adequately modeled as a combination of affective valences and cognitive valences. In this combination, affective valences consistently were slightly more prevalent. Participation in professional learning activities was influenced by valence expectation ranging from modest in the Reflection on Practice model to marginally in the Formal Training model. Presumably, there is a gap between readiness for action and actual participation.

The role of subjective norm took a variety of forms in the three models. In the Formal Training model, subjective norm only influenced feasibility expectation and perceived freedom of action. These influences did not show up in the Personal Study model where subjective norm only influenced affective and cognitive valences. In the Reflection on Practice model, subjective norm appeared to unfold its full potential with influences on affective and cognitive valences, on perceived freedom of action, sense of personal autonomy, and sense of personal competence, and directly on participation in Reflection on Practice activities.

In addition to the effects that are mediated by valences, our analyses disclosed also direct influences of motivational antecedents. In all models sense of personal autonomy showed a direct contribution to participation in professional learning activities, which in the case of Formal Training activities was even higher than the contribution of valence expectation. In the Personal Study model feasibility expectation contributed directly to actual participation. And in the Reflection on Practice model sense of personal competence made a small direct contribution to actual participation, as also did subjective norm.

Although the empirical data obviously did not provide an encompassing test of the Unified Model of Task-specific Motivation, we may conclude that our analyses provided substantial and promising level of support to the proposed constructs that are relevant to task-specific motivation and their relations. We will not repeat the merits of the UMTM, as they are sufficiently inventoried above. Instead, we will discuss some peculiarities of the empirical results and suggest questions for further research to illuminate their origins. 
The most striking aspect of our results is the difference between the models that somehow must find their causes in the disparities between different types of learning activities. From the relations between learning activities it was already concluded that professional learning activities are quite heterogeneous. What is important regarding the status of our model is that the results of the structural equation models show that the type of activity determines if and to what extent different components play a role in how that activity is motivated. In the theoretical account of the UMTM it was speculated that the impact of relatedness would depend on the social character of the intended activity involved (de Brabander \& Martens, 2014). From the examples scrutinized in this investigation it appears that differences between activities in how they are situated socially indeed made a difference. Activities subsumed under Reflection on Practice are more or less by definition social in character. These activities focus on how teachers in their school community organize teaching and learning (Kwakman, 2003). Thus we can understand that subjective norm played its apparent pervasive role. The path coefficients of subjective norm may have been small individually, but together they constituted a substantial effect. The other models were much smaller examples of the contribution of subjective norm. Especially, Formal Training activities often are part of the requirements of policies of the school board to promote professional development of the staff members. In a slightly different sense Clark, Livingstone, and Smaller (2012) identified a lack of integration of formal and informal learning of teachers. It is conceivable that this kind of activities is less or even not at all embedded in daily teaching practice. If that is the case, then it is not strange that subjective norm only influenced conditional aspects like perceived environmental support and perceived freedom of action. The activities subsumed under Personal Study might again be different, because the learning needs that guide these activities presumably have a stronger connection to daily teaching practices. Thus it makes sense that subjective norm in this case did contribute to affective and cognitive valences. Evidently, all this is rather speculative and requires further research. That research should, by way of precautionary note, not make the mistake to conceive socially situated activities just as activities are performed together with other people. Activities are socially situated to the extent they derive their meaning from socio-cultural definitions in one's reference group. Thus personal study as an individual activity can be more socially situated than a formal course of training, which, to be clear, is not to say that a specific formal course of learning cannot be embedded socially. On a higher level of abstraction we may conclude that differences between activities influence to what extent different components of the model become activated.

In the theoretical introduction it was suggested that task-specific antecedents influence readiness for action through their influence on valences. To take feasibility expectation as an example, a higher expectation of feasibility would produce higher levels of affective and cognitive valences that in turn would raise 
readiness for action. The examples we analyzed showed that the situation is much more complex and that these antecedents might directly enhance readiness for action as well. A stronger sense of personal autonomy directly "raised" participation (in the past) in all three categories of professional learning activities and therefore by definition increased readiness for action. This would imply that feeling in control, feeling self-responsible with respect to an activity itself already contributes to readiness for action. The status of this interpretation is very uncertain though, because it is complicated by the fact that sense of personal autonomy is conceptualized as having a reciprocal relation with affective valence. We also found signs of direct influences of feasibility expectation. In the Personal Study model feasibility expectation directly contributed to participation. And because feasibility expectation relied heavily on sense of personal competence, we take this to mean that to some extent readiness for action was directly boosted by higher levels of sense of personal competence. In the Reflection on Practice model a direct, though small contribution of sense of personal competence was found that bypassed feasibility expectation. In the Reflection on Practice model we found, furthermore, direct influences of subjective norm and of perceived relatedness on actual participation, the latter even without an accompanying influence on affective and/or cognitive valences. The results of our analysis indicated, therefore, that that it is necessary to make room in the UMTM for the possibility of direct effects of these antecedents on readiness for action. To some extent, people may gain readiness for action simply because they feel being origin of their action (sense of personal autonomy), see good opportunities for successful performance (feasibility expectation), experience positive relations to other people in the action context (sense of personal relatedness), and/or want to abide to relevant normative beliefs about that action (subjective norm). The explanation of these direct influences is not immediately clear, except perhaps in relation to the social components in our model. From research on goal contagion (Eren, 2009) it is known that people adopt, without necessarily being aware, goals that are prevalent in their social environment and that these goals guide action in the same way as consciously chosen goals would. These gregarious tendencies can clarify how sense of personal relatedness and subjective norm directly influence readiness for action bypassing affective and cognitive valences. Whatever the explanation of these phenomena, we need to repeat this investigation with different types of tasks and for that matter also in different types of professions to explore to what extent direct influences of motivational antecedents on readiness for action are constant effects and to what extent they depend on contextual characteristics.

Cognitive valences were found to be a rather homogeneous factor. This would imply that the different types of profit (personal, for the student and for the school) are not that different at all: what is good for me is good for others too. Although it is likely that these estimates of different types of profit will proof to be inherently related, we defer, however, the conclusion that the different profit 
aspects are completely interchangeable, because this outcome might very well be an artifact of our research method. The questions about different profits appeared in each other's neighborhood, and were worded almost identically. Responses may have been under influence of a halo effect. Even more importantly, the professional development activities that were presented may have been not concrete enough yet to evoke divergent responses.

An intriguing effect is the constant influence of perceived freedom of action on feasibility. It has the same order of magnitude as the factor loading of sense of personal competence. Apparently, for an action to be seen as feasible, teachers must perceive freedom (cf. Clark, Livingstone, \& Smaller, 2012). Another unexpected result is that perceived relatedness did not influence either affective valences or cognitive valences in any of the models. As there was no problem with the distribution of this variable or with its reliability, it contained enough systematic variance to have connections with other variables. For both phenomena we have no clue as to their explanation. They do remind us, however, of the topic of the isolation of the teacher that has received much attention in the past (Bakkenes, 1996; Bakkenes, de Brabander, \& Imants, 1999; Little, 1990; Lortie, 1975). This is not the place to expand on this topic further, but assuming that traditionally autonomy in the sense of being independent from other people in the school context is deeply rooted in the work conditions of the teacher, then freedom of action is a prerequisite for actions to be feasible and practice-based relations with colleagues are less relevant. However, such a picture nowadays seems a caricature of the job of teachers. With respect to perceived relatedness it also may have played a role that it was measured at a higher level than that of the task, though that would not necessarily have prevented perceived relatedness to influence or be influenced by other components of the UMTM.

Some of the paths in the three empirical models could have been modeled differently. The reciprocal relation between sense of personal autonomy and sense of personal competence is hardly open for other interpretations, because feelings of autonomy enhance feelings of competence and vice versa. In other less clear cases we have chosen the best possible option, but these choices are somewhat arbitrary. In each case we chose a direction by considering the possibility of both directions between components. We drew one-directional paths from perceived relatedness to subjective norm and to perceived external support. We judged relatedness to be basic, because close relations with colleagues promote both a tendency to follow their normative rules and the perception of their support. This is partly also because relatedness was measured at a less task-specific level. Perceived relatedness, and sense of personal relatedness for that matter, is a more stable characteristic of a certain context. Paths from subjective norm were presented as one-directional because it is less plausible that for instance perceived freedom of action or feasibility expectation increases the willingness to comply with prevailing adjudications of a specific action. However, other interpretations are possible. Reciprocal relations should not be confused with feed- 
back loops. Though feedback loops may start at different points in a flow chart, they remain essentially one-directional and exert their impact on a next occasion that exhibits enough similarity between occasions. Reciprocal relations on the other hand are relations in which both components covary at the same time.

The Unified Model of Task-specific Motivation proved to be a promising step towards the badly needed integration of motivation theories. Evidently, many more empirical tests are required. In that research the role of negative valences has to be included as well. Negative valences would enable us to inventory in a balanced way not only joys, but also burdens that are always both connected to any activity or course of action. Furthermore, in future research the use of more and different specific activities would be appropriate. The rather abstract level on which we defined our professional learning activities may have led our subjects to less specific reports than desirable. It is possible that some of our expected outcomes did not show up, because the categories of activities we used still were not specific enough. And finally, it will proof helpful to use also other sources of information than questionnaire data. Questions about feelings in the immediate neighborhood of questions about thoughts are bound to influence each other unwantedly. As far as cognitive valences are concerned, however, nothing is wrong with questioning people about them, because cognitive valences are explicit evaluations of expected consequences of actions. Questions about cognitive valences just ask the person to articulate them. For affective valences, however, we need also other indicators. Maybe that is also the case for some other components, like sense of personal relatedness or sense of personal autonomy, of the Unified Model of Task-specific Motivation.

\section{References}

Ajzen, I. (1991). The Theory of Planned Behavior. Organizational and Human Decision Processes, 50, 179-211. https://doi.org/10.1016/0749-5978(91)90020-T

Ajzen, I., \& Fishbein, M. (2008). Scaling and Testing Multiplicative Combinations in the Expectancy-Value Model of Attitudes. Journal of Applied Social Psychology, 38, 2222-2247. https://doi.org/10.1111/j.1559-1816.2008.00389.x

Bakkenes, I. (1996). Professional Isolation of Primary School Teachers: A Task-Specific Approach (Leiden). Doctoral Dissertation, Leiden: DSWO Press.

Bakkenes, I., de Brabander, C. J., \& Imants, J. G. M. (1999). Teacher Isolation and Communication Network Analysis in Primary Schools. Educational Administration Quarterly, 35, 166-202. https://doi.org/10.1177/00131619921968518

Bandura, A. (1977). Self-Efficacy: Toward a Unifying Theory of Behavioral Change. Psychological Review, 84, 191-215. https://doi.org/10.1037/0033-295X.84.2.191

Bandura, A. (1986). Social Foundations of Thought and Action. Englewood Cliffs, NJ: Prentice-Hall.

Bandura, A. (1992). On Rectifying the Comparative Anatomy of Perceived Control: Comments on "Cognates of Personal Control". Applied and Preventive Psychology, 1, 121-126. https://doi.org/10.1016/S0962-1849(05)80153-2

Bandura, A. (1997). Self-Efficacy: The Exercise of Control. New York, NY: W. H. Freeman \& Co. 
Bentler, P. M. (2008). EQS 6 Structural Equations Program Manual. Encino, CA: Multivariate Software, Inc.

Boekaerts, M., Van Nuland, H. J. C., \& Martens, R. L. (2010). Perspectives on Motivation: What Mechanism Energise Students' Behaviour in the Classroom. In K. Littleton, C. Wood, \& J. Kleine Staarman (Eds.), International Handbook of Psychology in Education (pp. 535-568). Bingley: Emerald Group Publishing Limited.

Carver, C. S. (2006). Approach, Avoidance, and the Self-Regulation of Affect and Action. Motivation and Emotion, 30, 105-110. https://doi.org/10.1007/s11031-006-9044-7

Clark, R., Livingstone, D. W., \& Smaller, H. (2012). Teacher Learning and Power in the Knowledge Society. Rotterdam: Sense Publishers. https://doi.org/10.1007/978-94-6091-973-2

Csikszentmihalyi, M. (1990). Flow: The Psychology of Optimal Experience. New York, NY: Harper \& Row.

De Brabander, C. J., \& Martens, R. L. (2014). Towards a Unified Theory of Task-Specific Motivation. Educational Research Review, 11, 27-44.

https://doi.org/10.1016/j.edurev.2013.11.001

De Brabander, C. J., Rozendaal, J. S., \& Martens, R. L. (2009). Investigating Efficacy Expectancy as Criterion for Comparison of Teacher- versus Student-Regulated Learning in Higher Education. Learning Environments Research, 12, 191-207. https://doi.org/10.1007/s10984-009-9062-y

de Brabander, K., Vinken, H., \& van Wolput, B. (2011). Competencies, Professional Development, School Climate, and Leraar24: A Panel Survey among Teachers 2010. Leraaar24 rapportenreeks, nummer 13, Heerlen: Ruud de Moor Centrum, Open University of the Netherlands.

Deci, E. L., \& Ryan, R. M. (2000). The "What" and "Why" of Goal Pursuits: Human Needs and the Self-Determination of Behaviour. Psychological Inquiry, 11, 227-268. https://doi.org/10.1207/S15327965PLI1104_01

Elliot, A. J. (2006). The Hierarchical Model of Approach-Avoidance Motivation. Motivation and Emotion, 30, 111-116. https://doi.org/10.1007/s11031-006-9028-7

Elliot, A. J., \& Church, M. A. (1997). A Hierarchical Model of Approach and Avoidance Achievement Motivation. Journal of Personality and Social Psychology, 72, 218-232. https://doi.org/10.1037/0022-3514.72.1.218

Elliot, A. J., \& Covington, M. V. (2001). Approach and Avoidance Motivation. Educational Psychology Review, 13, 73-92. https://doi.org/10.1023/A:1009009018235

Epstein, S. (1994). Integration of the Cognitive and the Psychodynamic Unconscious. American Psychologist, 49, 709-724. https://doi.org/10.1037/0003-066X.49.8.709

Eren, A. (2009). Exploring the Relationships among Mirror Neurons, Theory of Mind, and Achievement Goals: Towards a Model of Achievement Goal Contagion in Educational Settings. Educational Research Review, 4, 233-247.

https://doi.org/10.1016/j.edurev.2009.03.002

Imants, J. G. M., \& de Brabander, C. J. (1996). Sense of Efficacy of Teachers and Principals for Learner and School Oriented Tasks in Primary Schools. Teaching and Teacher Education, 12, 179-195. https://doi.org/10.1016/0742-051X(95)00053-M

Krapp, A. (2002). Structural and Dynamic Aspects of Interest Development: Theoretical Considerations from an Ontogenetic Perspective. Learning and Instruction, 12, 383-409. https://doi.org/10.1016/S0959-4752(01)00011-1

Krapp, A. (2005). Basic Needs and the Development of Interest and Intrinsic Motivational Orientations. Learning and Instruction, 15, 381-395. 
https://doi.org/10.1016/j.learninstruc.2005.07.007

Kwakman, K. (2003). Factors Affecting Teachers' Participation in Professional Learning Activities. Teacher and Teacher Education, 19, 149-170. https://doi.org/10.1016/S0742-051X(02)00101-4

Lang, P. J., Bradley, M. M., \& Cuthbert, B. N. (1998). Emotion, Motivation, and Anxiety: Brain Mechanisms and Psychophysiology. Biological Psychiatry, 44, 1248-1263. https://doi.org/10.1016/S0006-3223(98)00275-3

Little, J. (1990). The Persistence of Privacy: Autonomy and Initiative in Teachers' Professional Relations. Teachers College Record, 91, 509-536.

Lortie, D. C. (1975). Schoolteacher: A Sociological Study. Chicago: University of Chicago Press.

Reeve, J., Nix, G., \& Hamm, D. (2003). Testing Models of the Experience of Self-Determination in Intrinsic Motivation and the Conundrum of Choice. Journal of Educational Psychology, 92, 375-292. https://doi.org/10.1037/0022-0663.95.2.375

Ryan, R. M., \& Deci, E. L. (2000a). Self-Determination Theory and the Facilitation of Intrinsic Motivation, Social Development, and Well Being. The American Psychologist, 55, 68-78. https://doi.org/10.1037/0003-066X.55.1.68

Ryan, R. M., \& Deci, E. L. (2000b). Intrinsic and Extrinsic Motivations: Classic Definitions and New Directions. Contemporary Educational Psychology, 25, 54-67.

https://doi.org/10.1006/ceps.1999.1020

Schunk, D. H., Pintrich, P. R., \& Meece, J. L. (2008). Motivation in Education. Theory, Research, and Applications. Upper Saddle River, NJ: Pearson Education, Inc.

Smit, K., de Brabander, C. J., \& Martens, R. L. (2014). Student-Centred and Teacher-Centred Learning Environment in Pre-Vocational Secondary Education: Psychological Needs, and Motivation. Scandinavian Journal of Educational Research 58, 695-712. https://doi.org/10.1080/00313831.2013.821090

Wigfield, A., \& Eccles, J. S. (2000). Expectancy-Value Theory of Achievement Motivation. Contemporary Educational Psychology, 25, 68-81.

https://doi.org/10.1006/ceps.1999.1015 